МЕХАНИЗАЦИЯ, ЭЛЕКТРИФИКАЦИЯ,

АВ ТОМАТИЗАЦИЯ /

MECHANIZATION, ELECTRIFICATION, AUTOMATION

https://doi.org/10.30766/2072-9081.2020.21.2.183-198

УДК 621.313 .333

$(\mathrm{cc}) \mathrm{BY}$

Обоснование амгоритма управмения регумируемым эмектроприводом вамьцовых пмющияок-измемьчитемей фуражкного зерна

() 2020. М. А. Прищепов ${ }^{\bowtie}$, В. А. Дайнеко, Е. М. Прищепова

УО "Белорусский Государственный Аграрный Технический Университет", 2. Минск, Республика Беларусь

В последние годы наряду с традцционной технологией сухого хранения зерна и измельчения перед скармливанием широко используется технология консервирования плющеного зерна ранней стадии спелости. Названные технологии не заменяют друг друга, а объективно дополняют, то есть существуют параллельно и требуют соответствующего оборудования для их реализации. Для этого необходимо использовать универсальное энергоэффективное оборудование для плющения фуражного зерна с высокой годовой загруженностью. В качестве такого оборудования целесообразно использовать вальцовые плющилки-измельчители с индивидуальным электроприводом вальцов. На процесс плющения и измельчения зерна оказывают существенное влияние физико-механические свойства зерна и конструктивно- технологические параметры вальцовых плющцлок-измельчителей. Анализ прочностных свойств зерна показывает, что для уменьщения энергоемкости процесса плющения зерна его необходимо проводить при более высокой влажности и как можнно с более высокой скоростью деформации. При достижении определенной окружной скорости вальцов процесс достигает одновременно максимальной производительности и минимальной энергоемкости. В основу алгоритма управления заложсео изменение скорости вальцов ступенчато от меньщей скорости к больщей. При этом на каждой ступени производят плющение дозированной порции зерна, находящейся между верхней и нижней заслонками вертикальной загрузочной шахты, и измерение времени, за которое эта порция будет отработана. Эту процедуру проводят, изменяя скорость от меньшей к больщей до тех пор, пока не будет определена скорость, при которой плющение порции будет происходить за минимальное время. Если по технологическому процессу требуется режим измельчения зерна, то далее происходит увеличение скорости одного из вальцов уже от оптимальной скорости плющения. Увеличение скорости происходи до тех пор, пока будет расти ток рекуперации в параллельно соединённых иинах постоянного напряжения преобразователей частоты.

Ключевые слова: частотно-регулируемый электропривод, реологическая связь, энергоемкость, производительность, плютение, измельчение, физико-химические свойства, скорость деформации, оптимальная скорость плющения

Благодарности: работа выполнена в рамках ГПНИ 2011-2015 гг. «Инновационные технологии в АПК», подпрограмма «Инновационные технологии в животноводстве», задание 4.70: «Разработка и обоснование параметров ситемы многодвигательного частотно-регулируемого асинхронного электропривода вальцовых плющилок-измельчителей фуражного зерна», № госрегистрации 20142109.

Конфликт интересов: авторы заявили об отсутствии конфликта интересов.

Для цитирования: Прищепов М. А., Дайнеко В. А., Прищепова Е. М. Обоснование алгоритма управления регулируемым электроприводом вальцовых плющилок-измельчителей фуражного зерна. Аграрная наука Евро-СевероВостока. 2020;21(2):183-198. https://doi.org/10.30766/2072-9081.2020.21.2.183-198

Поступила: 03.02.2020 Принята к публикации: 11.03.2020 Опубликована онлайн: 21.04.2020

\title{
Substantiation of the algorithm for controlling the adjustable electric drive of roller crusher-grinders of forage grain
}

(c) 2020. Mikhail A. Pryshchepau ${ }^{\circledR}$, Vladimir A. Daineko, Alena M. Pryshchepava Belarusian State Agrarian Technical University, Minsk, Republic of Belarus

In recent years, along with the traditional technology of dry grain storage and grinding before feeding, the technology of preserving crushed grain at an early stage of ripeness is widely used. These technologies do not replace each other, but objectively complement each other, that is, they exist in parallel and require appropriate equipment for their implementation. To do this, it is necessary to use universal energy-efficient equipment for crushing feed grain with a high annual load. As such equipment, it is advisable to use roller crusher-grinders with individual electric drive of the rollers. The process

Аграрная наука Евро-Северо-Востока /

Agricultural Science Euro-North-East, 2020;21(2):183-198 
of crushing and grinding grain is significantly affected by the physical and mechanical properties of the grain and the design and technological parameters of roller crusher-grinders. Analysis of the strength properties of the grain shows that in order to reduce the energy intensity the process of crushing the grain must be carried out at a higher moisture content and the deformation rate should be as high as possible. When a certain circumferential speed of the rollers is reached, the process reaches both maximum performance and minimum energy consumption. The control algorithm is based on changing the speed of the rollers stepwise from a lower speed to a higher one. In this case, at each stage a metered portion of grain is crushed between the upper and lower flaps of the vertical loading shaft, and the time by which this portion will have been worked out is measured. This procedure is carried out by changing the speed from lower to higher until the speed at which crushing of the portion will take the minimum time is determined. If the technological process requires a grain grinding mode, the speed of one of the rollers increases from the optimal crushing rate. The speed increase occurs as long as the recuperation current in the parallel-connected DC buses of the frequency converters increases.

Keywords: frequency-controlled electric drive, rheological coupling, energy intensity, productivity, crushing, grinding, physical and chemical properties, deformation rate, optimal crushing rate

Acknowledgments: the work was carried out within the framework of the SPSR 2011-2015 "Innovative technologies in agriculture", the subprogram "Innovative technologies in animal husbandry", task 4.70: "Development and justification of parameters of the multi-motor frequency-controlled asynchronous electric drive of roller flatteners-feed grain grinders", state registration No. 20142109.

Conflict of interest: the authors declare no conflict of interest.

For citation: Pryshchepau M. A., Daineka V. A., Pryshchepava A. M. Substantiation of the algorithm for controlling the adjustable electric drive of roller crusher-grinders of forage grain. Agrarnaya nauka Evro-Severo-Vostoka = Agricultural Science Euro-North-East. 2020;21(2):183-198. (In Russ.). https://doi.org/10.30766/2072-9081.2020.21.2.183-198

\section{Received: 03.02.2020 Accepted for publication: 11.03.2020 Published online: 21.04.2020}

Республика Беларусь на протяжении последних пяти лет производит порядка 8-10 млн тонн зерна основных зерновых культур, из которых свыше $50 \%$ убирают на фуражные цели, причем после уборки для хранения его необходимо сушить, затем перед скармливанием измельчать, что требует больших капитальных вложений, значительных энерго- и трудозатрат, составляющих более $50 \%$ от общих трудозатрат в приготовлении комбикормов. Этим и обусловлен поиск более простых и дешевых приемов сохранения урожая, особенно фуражного зерна, которое можно скармливать животным непосредственно во влажном состоянии.

В последние годы наряду с традиционной технологией сухого хранения зерна и измельчения перед скармливанием широко используется технология консервирования плющеного зерна ранней стадии спелости. Последний сравнительно новый способ заготовки, хранения и использования фуражного зерна. Принцип хранения при этой технологии такой же, как и при силосовании трав, то есть кормовая масса хранится с использованием консерванта в герметичных условиях, препятствующих деятельности вредных микрорганизмов.

В настоящий период применяемые технологии не заменяют друг друга, а объективно дополняют, то есть существуют параллельно и требуют соответствующего оборудования для их реализации. Традиционная технология хранения и измельчения сухого зерна требует использования измельчающего оборудования, a технология консервирования плющенного влажного зерна - плющилок, как правило, вальцовых.

Практический опыт использования плющилок показывает, что в течение года они работают 2-3 недели и обладают низкой годовой загруженностью.

Цель исследований - обосновать целесообразность использования взаимосвязанного частотно-регулируемого асинхронного электропривода вальцов с предложенным алгоритмом управления в плющилках-измельчителях для повышения их годовой загруженности и энергоэффективности процессов плющения и измельчения фуражного зерна.

Материал и методы. Теоретические и экспериментальные исследования проведены в 2011-2017 гг. на базе УО «Белорусский Государственный Аграрный Технический Университет» на основе методов математического моделирования с использованием законов теоретической механики и механики материалов.

Результаты и их обсуждение. Теоретическое обоснование. Измельчение корма играет важную роль в усвоении питательных веществ организмом животных и птицы. Чем мельче частица (до определенного размера), тем быстрее она обрабатывается желудочным соком животного, птицы и лучше усваивается. Пылевидные частицы измельчаемого зерна, которых при измельчении молотковыми дробилками-измельчителями образуется до 20-30 \%, конгломерируются, и желудочный сок плохо проникает внутрь этих конгломератов (комков). 
Этот главный недостаток молотковых дробилок-измельчителей исключают вальцовые плющилки-измельчители. Работа вальцовых плющилок-измельчителей основана на сжатии (плющении), сдвиге и истирании зерна (материала). При вращении пары вальцов их поверхности затягивают зерно (материал) в межвальцовое пространство и разрушают его. Если линейная скорость образующих поверхностей вальцов одинаковая, то происходит плющение зерна, если скорость различная, то наряду с плющением зерна происходит и его сдвиг, что в итоге измельчает зерно.

При этом на процесс плющения и измельчения зерна оказывают существенное влияние физико-механические свойства зерна, к которым относятся объемная масса, плотность, влажность, форма и размеры зерновки, коэффициент трения, прочность, пленчатость, стекловидность $[1,2]$.

Достаточно системно, основываясь на исследованиях многих авторитетных авторов, процесс измельчения зерна на вальцовых станках изложен в работе [3], согласно которой первые работы в этом направлении были выполнены профессором П. А. Афанасьевым, установившим, что относительное сжатие зерна до его разрушения прямо пропорционально нагрузке на него. На основании проведенных исследований им была получена зависимость, позволяющая вычислять работу, необходимую для разрушения зерна сжатием. С. А. Чистов определял усилия разрушения зерна пшеницы при деформациях сжатия и среза и установил, что разрушающие усилия сжатия в 2-3 раза превышают усилия среза. Значительный вклад в изучение физико-механических свойств зерна при его деформации внес В. Я. Гиршсон, определивший на специальном прессе разрушающие усилия при растяжении, сжатии и сдвиге для целого зерна пшеницы и ржи и их анатомических частей. Им установлено, что разрушающие усилия среза как для целого зерна, так и для его составляющих в 3-5 раз меньше, чем при деформации сжатия. Аналогичные данные, подтверждающие эти выводы, были получены П. П. Тарутиным и Н. М. Орловым, Н. В. Врасским, П. Г. Демидовым, И. В. Крагельским, А. Л. Шполянской и другими исследователями. Проведенные исследования по изучению условий деформирования зерна при его измельчении на вальцевых станках существенно расширил и дополнил С. Д. Хусид, используя фундаментальные труды В. Д. Куз- нецова по физике твердого тела, в которых введено понятие о скорости деформации твердых тел, физический смысл которого связан со скоростью приложения разрушающих усилий к разрушаемому телу, скоростью уменьшения объема измельчаемого тела. Скорость деформирования твердых тел представляет собой первую производную от относительной деформации во времени. Увеличение скорости деформации твердых тел, как правило, приводит к их крупному разрушению. Исследования С. Д. Хусида показали, что скорость деформирования - это важный фактор в процессе измельчения зерновых продуктов, существенно влияющий на процесс их измельчения. Эндосперм пшеницы при влажности 13-14 \% представляет собой типично хрупкое тело, однако при определенных условиях силового нагружения он может проявлять свойства пластичных тел. Исследованиями установлено, что повышение влажности зерна приводит к увеличению пластичности зерна в целом и его анатомических частей. При этом несмотря на то, что снижается твердость эндосперма с повышением влажности зерна, его сопротивляемость разрушению в целом возрастает за счет еще большего возрастания сопротивляемости разрушению его оболочек. Поэтому при измельчении увлажненного зерна затраты энергии, как правило, больше, чем при измельчении сухого. Установленная закономерность наиболее резко выражена для низкостекловидного зерна.

При отрицательной температуре зерна (промораживании) зерно становится более хрупким, и прочность его понижается, а соответственно, уменьшаются и затраты энергии на его измельчение.

Рассматривая условия силового нагружения зерновки измельчаемого продукта в межвальцовом пространстве при разных линейных скоростях образующих вальцов можно утверждать, что на зерновку в точке захвата действуют две силы, одна из которых со стороны быстровращающегося вальца, вторая со стороны медленновращающегося. Эти силы направлены по касательной к окружности вальцов, причем первая, захватывает в межвальцовое пространство, а вторая выталкивает в силу разных окружных скоростей вальцов. После захвата зерновки в межвальцовое пространство на нее воздействуют также сжимающие силы, равные по величине, но направленные в противоположные стороны и зависящие от физико-механических свойств

Аграрная наука Евро-Северо-Востока /

Agricultural Science Euro-North-East, 2020;21(2):183-198 
зерна и межвальцового зазора. Таким образом, на зерновку, находящуюся в рабочей зоне, одновременно действуют сдвигающие и сжимающие усилия, определяющие характер и эффективность процесса измельчения. При этом необходимо учитывать не только величину этих усилий, но и их соотношение, которое определяется соотношением окружных скоростей вальцов, а их величина зависит от усилий сжатия измельчаемого зерна. Важна также скорость приложения этих усилий, то есть скорость деформации. С увеличением скорости деформации создаются условия для хрупкого разрушения как наиболее эффективного.

Подытоживая вышесказанное, можно отметить, что процесс измельчения зерна в межвальцовом пространстве определяется величиной и соотношением сдвигающих и сжимающих усилий, а также скоростью его деформирования, при этом эффективность измельчения возрастает с увеличением сдвигающих усилий и скорости деформирования.

Для подтверждения обоснованности сделанного выше вывода о влиянии скорости деформации на процесс измельчения было проведено изучение деформации зерновки пшеницы в условиях сжимаемости плоскими штампами и вальцами [4]. Из указанной работы вытекает, что на процесс деформирования зерна в большей степени влияют такие механические свойства, как упругость и вязкость. Упругость связана с первым этапом механического нагружения зерна, а вязкость с последующими этапами возрастания нагрузки. Исследования плющения зерна на прочностной машине Инстрон показали, что данный процесс можно описать обобщенной моделью Кельвина-Фойгта, согласно которой реологическая связь между напряжением и относительной деформацией зерновки примет следующий вид [5]:

$$
\sigma=\varepsilon E+\gamma \varepsilon \frac{d \varepsilon}{d t}
$$

где $\sigma$ - напряжение в зоне контакта плиты Инстрона и поверхности зерновки, $\varepsilon=\frac{\Delta l}{l}-$ относительная линейная деформация зерновки, $\Delta l$ - абсолютная линейная деформация зерновки, м, $l$ - толщина зерновки до деформации, м, $E$ - коэффициент упругости зерновки, Па, $\gamma$ - коэффициент вязкости зерновки, Па с, $t$ - время процесса деформирования, с, Па.

Во время плющения зерновки пятно (площадь) контакта растет, a толщина $l$ уменьшается до достижения Инстроном заданного максимального давления.
Зависимость силы давления плиты Инстрона от напряжения на поверхности контакта выражаем

$$
P_{z g}=\int_{0}^{\varepsilon} \sigma s d \varepsilon,
$$

где $s$ - площадь поверхности контакта зерновки с плитой деформатора, м $^{2}$.

Предположим, что скорость деформации постоянная, то есть $\frac{d \varepsilon}{d t}=v=$ const, тогда формула (2) примет вид:

$$
P_{z g}=\int_{0}^{\varepsilon} \varepsilon(E+\gamma v) s d \varepsilon
$$

После интегрирования имеем:

$$
P_{z g}=\frac{s \varepsilon^{2}}{2} \cdot(E+\gamma v) \text {. }
$$

Параметры $P_{z g}, s, \varepsilon, v$ определим из экспериментальных данных, полученных с помощью Инстрона. Из уравнения (4) мы можем найти любое одно неизвестное из двух $(\gamma, E)$ при условии, что другое известно.

Во время плющения зерновки пшеницы сорта Корвет на Инстроне были определены средние параметры процесса плющения: $P_{z g}=3000 \mathrm{H}, l=0,003 \mathrm{M}, \Delta l=0,0026 \mathrm{м}$, $s=0,00001 \mathrm{M}^{2}$.

В результате, после обработки экспериментальных исследований получены зависимости коэффициента вязкости $\gamma$ от изменения коэффициента упругости $E=500 \ldots 800$ мПа при разной продолжительности процесса плющения пшеницы $t$ :

$$
\begin{gathered}
\gamma=-0,1154 E+92,171, \text { МПа } \cdot \mathrm{c} \\
\text { при } t=0,1 \mathrm{c}(v=8,67 \mathrm{o} . \mathrm{e} / \mathrm{c}) ; \\
\gamma=-1,9357 E+1733,3, \mathrm{MПа} \cdot \mathrm{c} \\
\text { при } t=2 \mathrm{c}(v=0,43 \mathrm{o.e} / \mathrm{c}) ; \\
\gamma=-4,8393 E+4333,2, \mathrm{MПа} \cdot \mathrm{c} \\
\text { при } t=5 \mathrm{c}(v=0,17 \mathrm{o.e} / \mathrm{c}) .
\end{gathered}
$$

Из приведенных зависимостей очевидно, что коэффициент вязкости зерновки зависит от времени плющения. Чем больше время плющения, тем больший коэффициент вязкости. Работа, затраченная на деформирование зерна, определяется

$$
d A=\sigma d \varepsilon,
$$

где $A$ - удельная работа деформации или работа, отнесенная к объему зерновки, Па.

Аналогично удельная работа деформации при деформировании зерновки в плющилке определена в работе [4].

При этом сила давления вальцов на зерновку вычисляется по формуле

$$
P_{z g}=\frac{\pi}{8} r^{2} \sin ^{2} \alpha \varepsilon_{x}^{2}\left(E+\gamma v_{x}\right),
$$

где $r$ - радиус вальца, м, $\alpha$ - угол деформации зерновки, рад, $\varepsilon_{x}-$ относительная линейная 
деформация зерновки в межвальцовом пространстве, $v_{x}-$ скорость деформации зерновки в межвальцовом пространстве, м/с.

Из приведенных формул очевидно, что наилучшая эффективность плющения (сжатия) зерна будет при минимальной удельной работе деформации $A(5)$, а она будет наименьшей при минимальном напряжении б в зерновке (2) и соответственно силе давления $P_{z g}(4),(6)$. Детальный анализ полученных выражений (4) и (6) показывает, что величина силы давления в обоих выражениях будет определяться соотношением изменяющихся параметров выражения $E+\gamma v$ или $E+\gamma v_{x}$, так как остальные параметры в обоих выражениях можно принять постоянными. Использование зависимостей коэффициента вязкости от изменения коэффициента упругости зерновки пшеницы при разной скорости деформации показывает, что для одного и того же значения коэффициента упругости зерновки, при изменении скорости деформации в сторону увеличения, коэффициент вязкости будет уменьшаться. Значит, произведение их значений будет иметь минимум при определенных значениях скорости деформации и коэффициента вязкости и изменяться с изменением коэффициента упругости, что подтверждает результаты, полученные вышеуказанными исследователями.

Кроме физико-механических свойств зерна, на процесс плющения и измельчения зерна оказывают влияние конструктивные и технологические параметры вальцовых плющилок-измельчителей.

Работы исследователей В. И. Сыроватки $[6,7]$, В. С. Ромалийского [8], В. А. Сысуева $[9,10]$, П. А. Савиных $[11,12,13]$, В. А. Одегова $[11,14]$, А. И. Пунько и др. $[15,16]$ посвящены изучению влияния не только физико-механических свойств зерна, но и основных конструктивных и технологических параметров на такие важные показатели работы вальцовых плющилок-измельчителей, как производительность, энергоемкость, качество получаемого продукта, а также на распорное усилие между вальцами. При этом необходимо отметить, что наибольшее число работ посвящено исследованию зависимостей производительности и энергоемкости процессов плющения и измельчения зерна от окружной скорости образующих поверхностей вальцов, зазора между вальцами, диаметров вальцов, шага и угла заострения их рифлей, соотношения окружных скоростей вальцов для различных зерновых культур и различной влажности зерна. Что касается качества получаемого продукта, т. е. плющеного или измельченного зерна, то оно оценивается, как правило, степенью измельчения при плющении зерна или модулем помола при его измельчении. Степенью измельчения называют отношение характерного линейного размера до измельчения к соответствующему размеру зерна после плющения (толщине плющения зерна): рекомендуемая толщина для крупного рогатого скота - 1,0-1,8 мм, для свиней - 0,6-1,1 мм, птицы - 1,5-2,0 мм. Для зерен сферической формы характерный линейный размер зерна до измельчения равен его диаметру, для зерен вытянутой формы - толщине зерна. Качественным показателем измельчения зерна является модуль помола, который вычисляется по результатам ситового анализа как средневзвешенный диаметр частиц измельченного зерна. При этом гранулометрический состав измельченного зерна будет более выравненным, если на сите с самым крупным отверстием и под ситом с самым мелким отверстием будет находиться минимальное количество пробы измельченного зерна. Проведенные нами исследования и исследования других авторов показывают, что высев измельченного на вальцовых плющилках-измельчителях зерна под ситом с самым мелким отверстием в разы меньше аналогичного высева при измельчении зерна на молотковых дробилках, достигающего 20-30\% от массы измельченного зерна, что снижает эффективность скармливаемого корма. Степень измельчения зерна при его плющении определяется межвальцовым зазором, а модуль помола зерна при его измельчении определяется межвальцовым зазором и соотношением окружных скоростей образующих вальцов.

Известны работы [17, 18], в которых производится анализ влияния конструктивных параметров на производительность некоторых конструкций плющилок. Наиболее полно теоретический анализ влияния конструктивных параметров на производительность вальцовых плющилок-измельчителей при любом соотношении частот вращения и диаметров их вальцов, а также коэффициентов трения вальцов о зерновку и угле наклона плоскости, проходящей через их оси вращения к горизонтальной плоскости проведен в работе [19].

Из анализа результатов теоретических и экспериментальных исследований, изложенных в работах $[17,18,19,20]$ следует, что при определении производительности, а затем и мощности вальцовой плющилки-измельчителя

Аграрная наука Евро-Северо-Востока /

Agricultural Science Euro-North-East, 2020;21(2):183-198 
необходимо учитывать скольжение зерна по поверхности вальцов. Используя результаты исследований, изложенных в этих же работах $[17,18,19,20]$, можно считать, что при плющении зерна существует дуга на поверхности каждого вальца, в пределах которой зерновка испытывает деформацию и скользит по поверхности вальца. Тогда весь путь, проходимый зерновкой по вальцам, можно условно разделить на длины двух дуг: дуги деформации, ограниченной углом деформации, и длины дуги скольжения, ограниченной углом скольжения. Если длина дуги деформации практически однозначно определяется размерами и физико-механическими свойствами зерновки, а также зазором между вальцами, то длина дуги скольжения будет иметь гораздо более сложную зависимость, даже при плющении зерна. Если же рассматривать не только плющение, но и измельчение зерна вальцовыми измельчителями, то эта зависимость будет еще сложнее ввиду наличия в процессе измельчения зерна, кроме деформации и скольжения зерновки, сдвига, обусловленного разностью линейных скоростей образующих поверхностей вальцов.

В работе [19, 20] получена скорость зернового потока для плющилки с одинаковыми вальцами с учетом скольжения зерна

$$
v_{3}=\frac{D}{\frac{D}{v}+\frac{v-v_{0}}{\alpha_{1}\left(g+\frac{F}{m}\right)\left(f \sqrt{1-\left(\frac{D+b_{3}}{D+d_{H}}\right)^{2}}+\frac{D+b_{3}}{D+d_{H}}\right)}},
$$

где $D$ - диаметр вальцов, м, $v$ - линейная скорость образующих вальцов, м/c, $v_{0}$ - начальная скорость зерновки, м/с, $\alpha_{1}$ - угол деформации, рад, $g$ - ускорение свободного падения, м/ $\mathrm{c}^{2}$, $F$ - дополнительная внешняя сила, действующая на зерновку, H, $m$ - масса зерновки, кг, $f$ - коэффициент трения зерновки о вальцы, $b_{3}$ - зазор между вальцами, м, $d_{\text {н }}-$ средняя толщина (диаметр) зерновки, м.

Тогда объемная производительность плющилки определяется по общеизвестной формуле:

$$
Q=b_{3} v_{3} L
$$

где $L$ - длина вальцов, м.

$$
Q=\frac{\text { С учетом формулы (7): }}{\frac{L}{v}+\frac{L b_{3} D}{\alpha_{1}\left(g+\frac{F}{m}\right)\left(f \sqrt{1-\left(\frac{D+b_{3}}{D+d_{\mathrm{H}}}\right)^{2}}+\frac{D+b_{3}}{D+d_{\mathrm{H}}}\right)}} .
$$

Умножив объемную производительность на объемную массу зерна, можно получить массовую производительность в кг/с.

Учитывая, что максимальная объемная пропускная способность вальцов плющилки определяется по формуле

$$
Q_{\max }=b_{3} v L,
$$

то коэффициент использования максимальной пропускной способности плющилки $\left(0<k_{Q}<1\right)$

$$
k_{Q}=\frac{Q}{Q_{\max }}=\frac{b_{3} v_{3} L}{b_{3} v L}=\frac{v_{3}}{v},
$$

или

$$
k_{Q}=\frac{D}{D+\frac{v\left(v-v_{0}\right)}{\alpha_{1}\left(g+\frac{F}{m}\right)\left(f \sqrt{1-\left(\frac{D+b_{3}}{D+d_{\mathrm{H}}}\right)^{2}}+\frac{D+b_{3}}{D+d_{\mathrm{H}}}\right)}} .
$$

Анализ полученных выражений показывает, что увеличение скорости зернового потока и производительности плющилки возможно:

- увеличивая начальную скорость зерновки $v_{0}$ до линейной скорости образующих вальцов $v$;

- увеличивая коэффициент трения зерновки о вальцы $f$, а также диаметр вальцов $D$, так как в данном случае величина $\frac{D+b_{3}}{D+d_{\mathrm{H}}}=\cos \alpha_{1}$ будет иметь максимальное значение при любых реальных величинах зазора между вальцами $b_{3}$ и средних толщинах зерновки $d_{\mathrm{H}}$;

- приложением к силе тяжести зерновки дополнительной силы как в устройствах ${ }^{1}$, обеспечивающей ей дополнительное ускорение $a_{1}=\frac{F}{m}$.

Таким образом, обзор и анализ имеющихся теоретических и экспериментальных исследований показывает, что на процесс плющения и измельчения зерна вальцами оказывают в основном физико-механические свойства зерна и конструктивно-технологические параметры плющилок-измельчителей.

\footnotetext{
${ }^{1}$ Дайнеко В. А., Прищепова Е. М., Воробьев Н. А. Вальцовая плющилка зерна: пат. №14052 Республика Беларусь. Афіцыйны бюл. Нац. цэнтр інтэлектуал. уласнасці. 2011. №1. С. 84. Режим доступа: https:/ncip.by/upload/iblock/b93/b930612cca6c06eb8e5d16c35d494025.pdf; Дайнеко В. А., Прищепова Е. М., Воробьев Н. А., Карпович М. К. Вальцовая плющилка зерна: пат. №14696 Республика Беларусь. Афіцыйны бюл. Нац. цэнтр

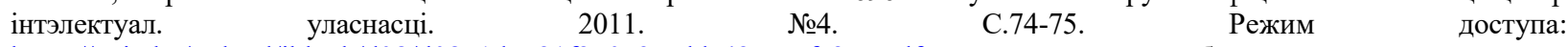
https://ncip.by/upload/iblock/d08/d0871d7721f25053aadda4255acfc27a.pdf; Шило И.Н., Воробьев Н.А., Прищепова Е.М. Вальцовая плющилка зерна: пат. №15375 Республика Беларусь. Афіцыйны бюл. Нац. цэнтр інтэлектуал. уласнасці. 2012. №1. С.72. Режим доступа: https://ncip.by/upload/iblock/b09/b093e2db77ba216adb808aabddda7ace.pdf
} 
Как показывает анализ физико-механических свойств зерна, увеличение его влажности способствует повышению коэффициента трения зерновки о поверхность вальца, пластичности зерна в целом и его анатомических частей, а также снижению твердости эндосперма зерна.

Анализ прочностных свойств зерна показывает, что для уменьшения энергоемкости процесса плющения зерна, его необходимо проводить при более высокой влажности зерна и как можно с более высокой скоростью деформации. Однако, этот процесс увеличения скорости деформации не бесконечен, при достижении определенной окружной скорости вальцов процесс достигает одновременно максимальной производительности и минимальной энергоемкости с последующим снижением производительности и повышением энергоемкости за счет проскальзывания рабочей поверхности вальцов относительно зерна. Причем эти взаимопротивоположные экстремумы производительности и энергоемкости существуют при разной окружной скорости вальцов для различных диаметров вальцов, межвальцовых зазоров, влажности и виде зерновых культур. Существенное влияние на мощность привода вальцов плющилки оказывает зазор между вальцами, диаметр вальцов, окружная скорость вальцов и тип их рабочей поверхности.

При вращении вальцов навстречу друг другу с разной окружной скоростью их рабочих поверхностей зерно будет испытывать одновременно сжатие, сдвиг, истирание, а при наличии рифлей на вальцах и резание в соизмеримых соотношениях, что делает процесс сложным в определении и настройке его технологических параметров, обеспечивающих необходимую степень измельчения зерна и высокие энергетические показатели процесса измельчения.

Обобщая рассмотренные выше исследования, можно сделать вывод, что полученные многими исследователями зависимости для определения производительности и мощности вальцовой плющилки, энергоемкости процесса сложны и ограничены для использования в расчетах, так как включают эмпирические коэффициенты, рассчитанные для конкретных конструкций, узкого диапазона изменения конструктивных и технологических параметров. В подавляющем большинстве в них не учитывается также скольжение зерна по рабочей поверхности вальцов, что не позволя- ет использовать их для достоверного обоснования параметров и режимов работы плющилок при создании более совершенных образцов, обеспечивающих плавное регулирование окружной скорости вальцов для определения взаимопротивоположных экстремумов производительности и энергоемкости. Еще в большей мере усложняется этот вопрос при использовании плющилки в качестве измельчителя, то есть при вращении вальцов с разной окружной скоростью, где еще требуется регулирование окружной скорости вальцов друг относительно друга.

Экспериментальные исследования. Для проверки правильности высказанной гипотезы и адекватности полученных выражений была проведена их экспериментальная проверка на установке с гладкими вальцами.

Подача зерна в межвальцовое пространство осуществлялась не традиционно используемым способом, то есть самотеком из сужающегося к межвальцовому пространству бункера, а через симметрично установленную относительно межвальцового зазора вертикальную с прямоугольным поперечным сечением загрузочную шахту. Один из размеров вышеуказанного сечения загрузочной шахты равен длине вальцов, а второй, ширина $b_{\text {ш }}$ - диаметру вальца. При этом шахта была оборудована сверху поршнем, обеспечивающим заданное давление на зерно, а снизу клапаном, принудительно открываемым для выгрузки зерна из шахты при эксперименте. Для электропривода вальцов плющилки использовались асинхронные двигатели с преобразователями частоты питающего напряжения. Эксперимент проводился в следующей последовательности. В загрузочную шахту под поршень загружалась определенная порция зерна, преобразователями частоты устанавливались необходимые частоты вращения вальцов. Затем открывался клапан для подачи зерна в межвальцовое пространство, при этом измерялась мощность, затрачиваемая на плющение, и время с момента открытия клапана до окончания процесса плющения. При эксперименте изменялась частота вращения вальцов $n$, сила давления на поршень, соответственно, и на зерно $F$, при постоянном межвальцовом зазоре $b_{3}$, ширине $b_{\text {ш }}$ в нижней части шахты в направлении, перпендикулярном осям вальцов. Результаты проведенного эксперимента представлены на рисунках 1 и 2 [21].

Аграрная наука Евро-Северо-Востока /

Agricultural Science Euro-North-East, 2020;21(2):183-198 


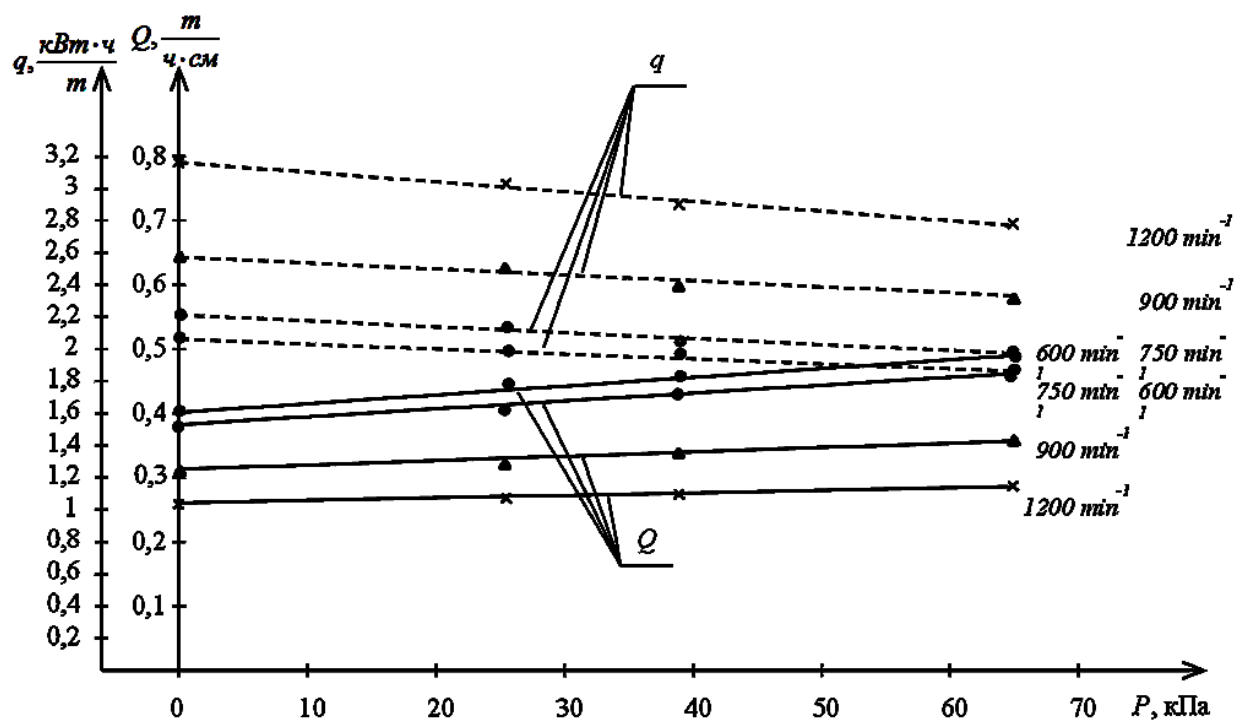

Puc. 1. Графики изменения удельной производительности $Q$ и энергоемкости $q$ плющилки для различных частот вращения вальцов $n$ при изменении давления $P$ в загрузочной шахте $\left(b_{3}=1\right.$ мм, $b_{\text {ш̈ }}=40$ мм $) /$

Fig. 1. Graphs of changes in the specific productivity $Q$ and energy intensity $q$ of the crusher for different speeds of rotation of the rollers $n$ when the pressure $P$ changes in the loading shaft $\left(b_{\text {gap }}=1 \mathrm{~mm}, b_{w}=40 \mathrm{~mm}\right)$

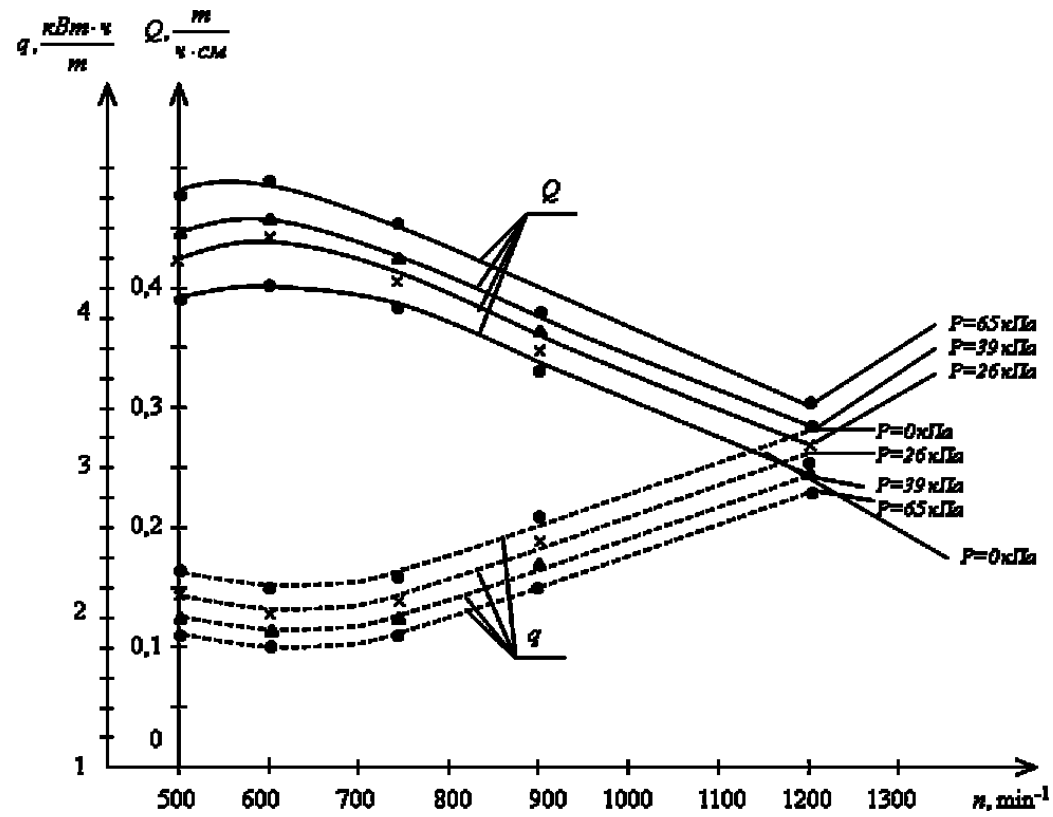

Рис. 2. Графики изменения удельной производительности $Q$ и энергоемкости $q$ вальцевой плющилки для различных давлений $P$ в загрузочной шахте при изменении частоты вращения вальцов $n\left(b_{3}=1\right.$ мм, $b_{u}=40$ мм $) /$

Fig.2. Graphs of changes in the specific productivity $Q$ and energy intensity $q$ of the roller crusher for different pressure $P$ in the loading shaft when changing the rotation frequency of the rollers $n\left(b_{\text {gap }}=1 \mathrm{~mm}\right.$, $\left.b_{w}=40 \mathrm{~mm}\right)$

Для того чтобы вальцовая плющилкаизмельчитель выполняла технологические процессы плющения и измельчения зерна и обеспечивала высокую энергоэффективность процессов в ней необходимо использовать взаимосвязанный частотно-регулируемый асинхронный электропривод для каждого из вальцов в отдельности, схема силовой части кото- рого представлена на рисунке 3 . Предложенная схема при наиболее энергоемком процессе измельчения зерна обеспечивает рекуперацию электрической энергии (около 20 \%) по шинам постоянного тока от асинхронного двигателя АД медленновращающегося вальца к АД быстровращающегося вальца [22, 23]. При этом в работе [24] показано, что минимум удельных 
приведенных затрат при высокой загрузке плющилки-измельчителя будет обеспечиваться минимизацией удельных энргозатрат процессов плющения и измельчения зерна, то есть

$$
q=\frac{P}{Q} \rightarrow \min
$$

Учитывая, что мощность, потребляемая электроприводом плющилки-измельчителя $P$, и производительность плющилкиизмельчителя $Q$ напрямую зависят от скорости вальцов, то задача алгоритма управления сводится к поиску скорости вальцов, при которой удельные энергозатраты будут минимальными.

Справедливость этого вытекает и из баланса мощности, затрачиваемой электроприводом на плющение

$$
P_{\text {пл }}=\frac{P_{\text {тр.с }}+P_{\text {д }}+P_{\text {тр.п }}}{\eta},
$$

где $P_{\text {тр.с }}-$ мощность трения скольжения поверхности вальцов по зерновке, Вт, $P_{\text {д }}$ мощность деформации зерновки, Вт, $P_{\text {тр.п }}-$ мощность трения в опорных подшипниках вальцов, Вт, $\eta$ - КПД привода.

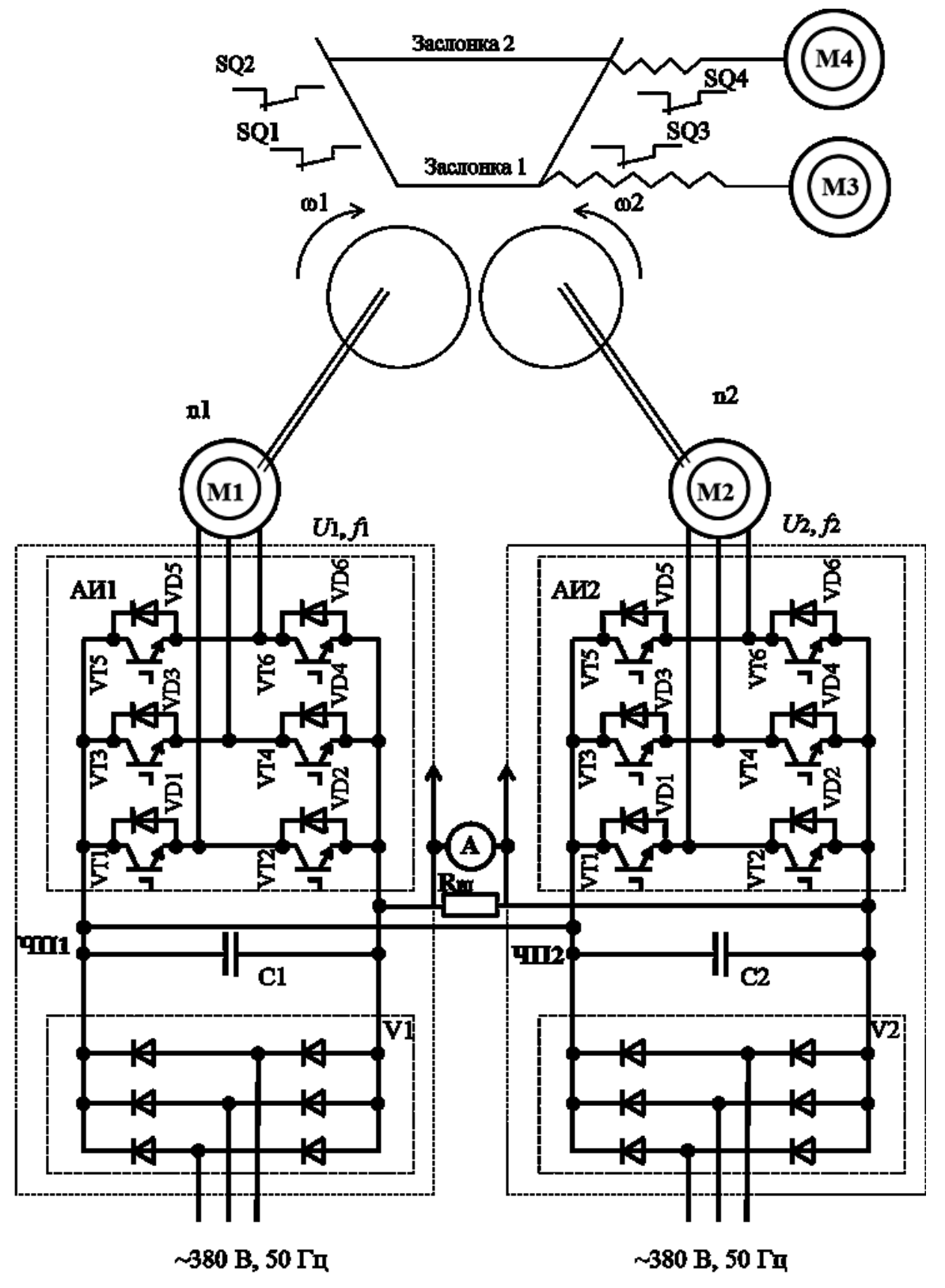

Рис. 3. Схема силовой части системы управления взаимосвязанного частотно-регулируемого асинхронного электропривода /

Fig. 3. Diagram of the power part of the control system of an interconnected frequency-controlled asynchronous electric drive 
Учитывая, что мощность трения скольжения вальцов по зерновке $P_{\text {тр.с и мощность }}$

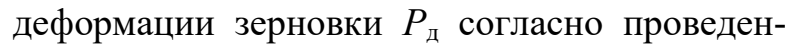
ному выше анализу процесса деформации с помощью обобщенной модели КельвинаФойгта [4] будут иметь минимум при определенных скоростях вальцов. При этом скорость минимума мощности трения скольжения будет определяться динамическим коэффициентом трения скольжения, а скорость минимума мощности деформации - значением скорости деформации и коэффициента вязкости зерна. Следовательно, ввиду сложности вышеуказанных зависимостей совпадения минимумов мощностей при одной скорости маловероятно. Однако при определенной скорости будут обеспечиваться минимальные суммарные затраты мощностей в электроприводе плющилки, а, соответственно, и наибольшая подача зерна из-за минимального его проскальзывания на вальцах.

Для непосредственной технической реализации алгоритма управления электроприводом с обоснованной целевой функцией и критерием оптимизации необходимо за определенный промежуток времени определять среднеинтегральную потребляемую из сети мощность электропривода и среднеинтегральную производительность плющилки-измельчителя зерна при изменении скорости вальцов. Если измерение среднеинтегральной потребляемой из сети мощности электропривода не вызывает технических сложностей, то измерение среднеинтегральной производительности вальцовой плющилки-измельчителя весьма проблематично. Это обусловлено отсутствием высокоточных серийно выпускаемых поточных расходомеров зерна, ввиду того, что на точность их измерений существенно оказывают влияние влажность, температура, плотность зернового потока и вид культуры.

Наиболее просто и с достаточной для практической реализации точностью измерение производительности плющилки-измельчителя можно осуществить путем измерения времени плющения дозированной объемной порции зерна, находящегося в вертикальной шахте загрузки плющилки-измельчителя между нижней и верхней заслонками (рис. 4).

Таким образом, техническая реализация способа управления возможна через нахождение такой скорости вальцов, при которой дозированная объемная порция зерна будет обработана за минимальное время.

При реализации процесса измельчения зерна в балансе мощности, затрачиваемой электроприводом на измельчение $P_{\text {изм }}$, необходимо дополнительно учитывать мощность, затрачиваемую на сдвиг зерновки $P_{\text {сдв }}$ и мощность проскальзывания вальцов по зерновке $P_{\text {проск }}$ при сдвиге, т. е.

$$
P_{\text {изм }}=\frac{P_{\text {тр.с }}+P_{\text {д }}+P_{\text {тр.п }}+P_{\text {сдв }}+P_{\text {проск }}}{\eta} .
$$

Из приведенного выражения, очевидно, что первые три составляющие баланса мощности будут иметь те же оптимальные значения, что и при плющении зерна, мощность, затрачиваемая на сдвиг зерна $P_{\text {сдв }}$ также должна быть определенной и будет определяться модулем упругости и размером зерна, межвальцовым зазором и геометрическими размерами вальцов, а мощность проскальзывания вальцов по зерновке $P_{\text {проск при сдвиге }}$ будет определяться также модулем упругости и размером зерна, межвальцовым зазором и геометрическими размерами вальцов, и кроме того, соотношением разности скоростей вальцов. Следовательно, регулируя соотношение разности скоростей вальцов можно влиять на величину этой составляющей и соответственно на общий баланс мощности.

После того, как найден оптимальный скоростной режим плющения зерна, необходимо увеличивать скорость на одном из вальцов до тех пор, пока будет расти ток рекуперации $I_{p}$ в перемычках шин постоянного напряжения преобразователей частоты. Если при некотором увеличении скорости одного из вальцов прекратится увеличение тока рекуперации $I_{p}$, то это значит, что начинает расти бесполезная составляющая баланса мощности

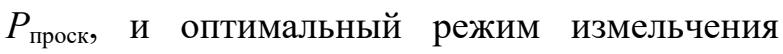
зерна уже достигнут [25]. Дальнейшее увеличение скорости быстровращающегося вальца будет вести к увеличению удельных энергозатрат на измельчение зерна.

Для пояснения вышесказанного на рисунке 4 приведена блок-схема алгоритма управления взаимосвязанными электроприводами вальцовых плющилок-измельчителей зерна с рекуперацией электрической энергии, где в блоке 1 оговорено исходное состояние заслонок вертикальной шахты загрузки зерна. 







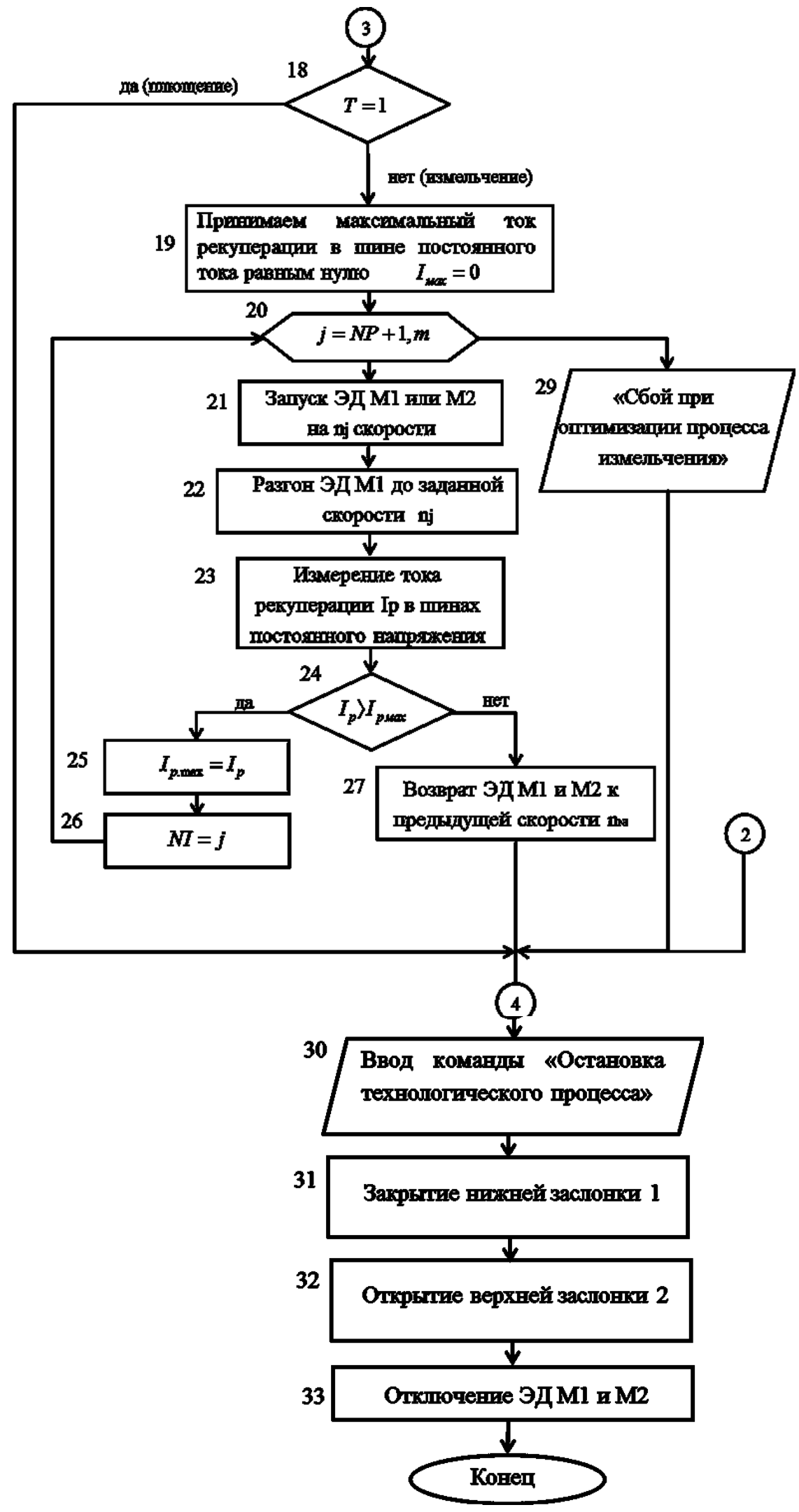

Рис. 4. Блок-схема алгоритма управления взаимосвязанными электроприводами вальцов плющилки-измельчителя зерна с рекуперацией электрической энергии /

Fig. 4. Block diagram of the algorithm for controlling the interconnected electric drives of the rollers of grain crusher-grinder with electric energy recovery 
В основу алгоритма управления заложено изменение скорости вальцов ступенчато (m ступеней) от меньшей скорости к большей. В блок-схеме алгоритма скорости вальцов и технологический режим работы плющилкиизмельчителя задаются в блоке 2. При этом на каждой ступени производят плющение дозированной порции зерна, находящейся между верхней и нижней заслонками вертикальной загрузочной шахты, и измерение времени за которое эта порция будет отработана. Эту процедуру проводят от меньшей скорости к большей до тех пор, пока не определена скорость, при которой плющение порции будет происходить за минимальное время. В блок-схеме алгоритма управления электроприводом эта процедура будет реализовываться в блоках 3-17.

Если по технологическому процессу требуется режим измельчения зерна (блок 18), то далее происходит увеличение скорости одного из вальцов уже от оптимальной скорости плющения. Увеличение скорости происходит до тех пор, пока растет сила тока рекуперации $I_{p}$ в перемычках шин постоянного напряжения преобразователей частоты. Эта процедура будет реализовываться в блоксхеме алгоритма в блоках 19-27. В блоках 28-29 будет выдаваться сообщение о том, что оптимизация скоростного режима еще не достигнута, то есть необходимо увеличить количество ступеней скорости или дискретность между ступенями.

В блоках 30-33 заложена процедура выключения плющилки-измельчителя с возвратом верхней и нижней заслонок шахты загрузки в исходное состояние и остановкой приводных двигателей М1 и М2.

Использование предлагаемого способа управления взаимосвязанными электроприводами вальцовой плющилки-измельчителя зерна позволит минимизировать удельные энергозатраты на выполнение технологических операций плющения и измельчения зерна путем задания оптимальных скоростных режимов взаимосвязанной работы электроприводов.

\section{Выводы.}

1. Приведенные в статье исследования показывают, что на энергоэффективность процессов плющения и измельчения фуражного зерна существенное влияние оказывают его физико-механические свойства и конструктивно-технологические параметры плющилкиизмельчителя зерна.

2. Любое изменение физико-механических свойств обрабатываемого зерна приводит и к изменению реологической связи между напряжением и относительной деформацией зерновки (к изменению параметров обобщенной модели Кельвина-Фойгта), что в свою очередь повлечет необходимость изменения технологических параметров обработки зерна (скорости плющения зерна).

3. Для того чтобы вальцовая плющилка могла выполнять функции плющения и измельчения зерна, обеспечивая тем самым высокую ее годовую загруженность, необходимо использовать индивидуальный регулируемый привод каждого из вальцов.

4. Высокая энергоэффективность работы вальцовых плющилок-измельчителей в режиме плющения обеспечивается синхронным регулированием скорости вращения вальцов до достижения максимальной производительности плющилки-измельчителя зерна, а в режиме измельчения еще дополнительным увеличением скорости вращения одного из вальцов до тех пор, пока будет увеличиваться ток рекуперации в параллельно соединённых шинах постоянного напряжения частотных преобразователей приводных двигателей вальцов.

5. Минимум удельных энергозатрат в процессах плющения и измельчения зерна наиболее просто контролировать через производительность процесса путем измерения времени плющения дозированной объемной порции зерна, находящегося в вертикальной шахте загрузки плющилки-измельчителя между ее нижней и верхней заслонками, так как максимуму производительности процесса плющения соответствует минимум удельных энергозатрат.

\section{Список литературы}

1. Мельников С. В. Механизация и автоматизация животноводческих ферм. Л.: Колос - Ленинградское отд-ние, $1978.560 \mathrm{c.}$

2. Кукта Г. М. Технология переработки и приготовления кормов. М.: Колос, 1978. 240 с.

3. Мерко И. Т. Совершенствование технологических процессов сортового помола пшеницы. М.: Колос, 1979. 189 с.

4. Чигарев О. Ю., Прищепова Е. М. Некоторые подходы в вопросах деформирования зерна. Агропанорама. 2013;(6):18-20. Режим доступа: https://rep.bsatu.by/handle/doc/7041

Аграрная наука Евро-Северо-Востока /

Agricultural Science Euro-North-East, 2020;21(2):183-198 
5. Ишлинский А. Ю. Прикладные задачи механики. М.: Наука, 1986. Т. 1. С. 372.

6. Сыроватка В. И., Сергеев Н. С. Изыскание энергосберегающих рабочих органов для измельчения семян рапса и фуражного зерна. Научные труды ГНУ ВНИИМЖ Россельхозакадемии. 2008;(3):3-12.

7. Сыроватка В. И. Использование высоковлажного фуражного зерна в животноводстве. Труды ГОСНИТИ. 2007;(100):127-131. Режим доступа: https://www.elibrary.ru/item.asp?id=15004055

8. Ромалийский В. С. Инновационная техника и ресурсосберегающие технологии для приготовления комбикормов в хозяйствах. Вестник Всероссийского научно-исследовательского института механизации животноводства. 2016;(3(23)):158-162.

9. Сысуев В. А., Казаков В. А. Новые технологии послеуборочной технологии послеуборочной переработки зерна и получения высококачественных кормов для животноводства. Аграрная наука Евро-СевероВостока. 2015;(5(48)):73-79. Режим доступа: https://www.elibrary.ru/item.asp?id=24113608

10. Сысуев В. А., Савиных П. А., Казаков В. А. Движение зерновки в подводящем канале плющилки зерна. Вестник Всероссийского научно-исследовательского института механизации животноводства. 2015;(4(20)):19-24.

11. Одегов В. А., Савиных П. А., Казаков В. А., Поляков С. М. Исследование влияния диаметра и окружной скорости вальцов с гладкой рабочей поверхностью на процесс двухстадийного плющения. Вестник НГИЭИ. 2018;(1(80)):44-55. Режим доступа: https://www.elibrary.ru/item.asp?id=32324573

12. Савиных П. А., Казаков В. А., Мошонкин А. М. Теоретические исследования и конструктивная разработка двухступенчатой плющилки зерна. Вестник Всероссийского научно-исследовательского института механизации животноводства. 2017;(3(27)):91-97.

13. Савиных П. А., Казаков В. А., Мошонкин А. М. Экспериментально-теоретические исследования питающего устройства плющилки зерна. Вестник Всероссийского научно-исследовательского института механизации животноводства. 2019;(3(35)):61-68.

14. Одегов В. А., Комкин А. С., Шилин В. В. Исследование влияния окружной скорости вальцов и влажности материала на основные показатели рабочего процесса двухступенчатого вальцового станка. Пермский Аграрный Вестник. 2018; (1(21)):28-33. Режим доступа: https://www.elibrary.ru/item.asp?id=32664910

15. Пунько А. И., Романчук Д. И., Савиных В. Н., Гуд А. Н. Анализ конструкций вальцовых измельчителей зернофуража. Механизация и электрификация сельского хозяйства. Межведомственный тематический сборник. 2011;(45): 172-178. Режим доступа: https://www.elibrary.ru/item.asp?id=30716940

16. Савиных В. Н., Романчук Д. И., Воробьев Н. А. Результаты испытаний плющилки влажного зерна ПВ3-10. Механизация и электрификация сельского хозяйства. Межведомственный тематический сборник (к 80-летию со дня образования НАН Беларуси). 2008;(42): 210-214. Режим доступа: https://www.elib-rary.ru/item.asp?id=35369746

17. Воробьёв Н. А. Теоретические исследования производительности вальцовой плющилки. Агропанорама. 2008;(2):45-48. Режим доступа: https://rep.bsatu.by/handle/doc/1263

18. Дайнеко В. А., Прищепова Е. М. Математическое моделирование мощности вальцовой плющилки зерна. Ukrainian Food Journal. 2012; (3):40-49. Режим доступа: http://www.ufj.ho.ua/

19. Дайнеко В. А., Прищепова Е. М. Теоретическое обоснование производительности вальцовой плющилки-измельчителя. Агропанорама. 2012;(2):14-28. Режим доступа: https://rep.bsatu.by/handle/doc/7245

20. Шило И. Н., Воробьев Н. А., Прищепова Е. М. К обоснованию мощности привода вальцов плющилки. Агропанорама. 2008;(3):25-28. Режим доступа: https://rep.bsatu.by/handle/doc/1280

21. Дайнеко В. А., Прищепова Е. М. К вопросу повышения производительности и снижения удельных энергозатрат вальцовой плющилки зерна. Агропанорама. 2013;(2):24-27. Режим доступа: $\underline{\text { https://rep.bsatu.by/handle/doc/6398? mode=full }}$

22. Прищепов М. А., Гурин В. В., Прищепова Е. М., Иванов Д. М. Устройство управления взаимосвязанными частотно-регулируемыми асинхронными электроприводами с рекуперацией электрической энергии (варианты): пат. № 21618 Республика Беларусь. № а 20150506; заяв. 26.10.2015; опубл. 28.02.2018. Афіцыйны бюл. Нац. цэнтр інтэлектуал. уласнасці. 2018. №1. С. 158. Режим доступа: https://ncip.by/upload/iblock/f5a/f5a1dfcb7efc24c148aeebb6b129fa29.pdf

23. Прищепов М. А., Гурин В. В., Прищепова Е. М., Иванов Д. М. Способ управления взаимосвязанными электроприводами с рекуперацией электрической энергии: пат. № 19919 Республика Беларусь. № a 20131163; заяв. 08.10.2013; опубл. 28.02.2016. Афіцыйны бюл. Нац. цэнтр інтэлектуал. уласнасці. 2016. №1. С. 133. Режим доступа: https://ncip.by/upload/iblock/7b1/7b122278043fa35fd69d4258c4cb09ee.pdf

24. Дайнеко В. А., Гургенидзе И. И., Прищепова Е. М. Обоснование целевой функции и критерия оптимизации конструктивных и технологических параметров системы электропривода вальцовых плющилок-измельчителей зерна. Агропанорама. 2015;(4):30-35. Режим доступа: https://rep.bsatu.by/handle/doc/4176

25. Прищепова Е. М., Дайнеко В. А. Способ управления взамосвязанными приводами вальцовой плющилки-измельчителя зерна с рекуперацией электрической энергии: пат. №21847 Республика Беларусь. № a 20150636; заяв. 16.12.2015; опубл. 30.04.2018. Афіцыйны бюл. Нац. цэнтр інтэлектуал. уласнасці. 2018. №2. С. 77-78. Режим доступа: https://ncip.by/upload/iblock/b43/b4369672f12b7716e201e2bcd49634a5.pdf 


\section{References}

1. Mel'nikov S. V. Mekhanizatsiya i avtomatizatsiya zhivotnovodcheskikh ferm. [Mechanization and automation of livestock farms]. Leningrad: Kolos - Leningradskoe otd-nie, 1978. 560 p.

2. Kukta G. M. Tekhnologiya pererabotki i prigotovleniya kormov. [Technology of processing and preparation of feed]. Moscow: Kolos, 1978. 240 p.

3. Merko I. T. Sovershenstvovanie tekhnologicheskikh protsessov sortovogo pomola pshenitsy. [Improvement of technological processes of varietal wheat grinding]. Moscow: Kolos, 1979. 189 p.

4. Chigarev O. Yu., Prishchepova E. M. Nekotorye podkhody v voprosakh deformirovaniya zerna. [Some approaches in the issues of grain deformation. Agropanorama] Agropanorama. 2013;(6):18-20. URL: https://rep.bsatu.by/handle/doc/7041

5. Ishlinskiy A. Yu. Prikladnye zadachi mekhaniki. [Applied problems of mechanics]. Moscow: Nauka, 1986. Vol.1. pp. 372.

6. Syrovatka V. I., Sergeev N. S. Izyskanie energosberegayushchikh rabochikh organov dlya izmel'cheniya semyan rapsa i furazhnogo zerna. [Research of energy- saving working bodies for grinding rapeseed and feed grain]. Nauchnye trudy GNU VNIIMZh Rossel'khozakademii. 2008;(3):3-12.

7. Syrovatka V. I. Ispol'zovanie vysokovlazhnogo furazhnogo zerna v zhivotnovodstve. [Use of high- moisture feed grain in animal husbandry]. Trudy GOSNITI. 2007;(100):127-131. URL: https://www.elibrary.ru/item.asp?id=15004055

8. Romaliyskiy V. S. Innovatsionnaya tekhnika i resursosberegayushchie tekhnologii dlya prigotovleniya kombikormov $v$ khozyaystvakh. [Innovation technology and resource-saving technologies for preparation of mixed fodders at farms]. Vestnik Vserossiyskogo nauchno-issledovatel'skogo instituta mekhanizatsii zhivotnovodstva. 2016;(3(23)):158-162.

9. Sysuev V. A., Kazakov V. A. Novye tekhnologii posleuborochnoy tekhnologii posleuborochnoy pererabotki zerna $i$ polucheniya vysokokache-stvennykh kormov dlya zhivotnovodstva. [New technologies of post-harvest processing of grain and obtaining of high-quality fodders for animal husbandry]. Agrarnaya nauka Evro-Severo-Vostoka = Agricultural Science Euro-North-East. 2015;(5(48)):73-79. URL: https://www.elibrary.ru/item.asp?id=24113608

10. Sysuev V. A., Savinykh P. A., Kazakov V. A. Dvizhenie zernovki v podvodyashchem kanale plyushchilki zerna. [Theoretical research and design development of a two-stage grain crusher]. Vestnik Vserossiyskogo nauchno-issledovatel'skogo instituta mekhanizatsii zhivotnovodstva. 2015;(4(20)):19-24. (In Russ.).

11. Odegov V. A., Savinykh P. A., Kazakov V. A., Polyakov S. M. Issledovanie vliyaniya diametra i okruzhnoy skorosti val'tsov s gladkoy rabochey poverkhnost'yu na protsess dvukhstadiynogo plyushcheniya. [A study of the influence of the diameter and the circumferential speed of the rollers with a smooth working surface for the two-stage crimping process]. Vestnik NGIEI = Bulletin NGII. 2018;(1(80)):44-55. URL: https://www.elibrary.ru/item.asp?id=32324573

12. Savinykh P. A., Kazakov V. A., Moshonkin A. M. Teoreticheskie issledovaniya $i$ konstruktivnaya razrabotka dvukhstupenchatoy plyushchilki zerna. [Theoretical research and design development of a two-stage grain crusher]. Vestnik Vserossiyskogo nauchno-issledovatel'skogo instituta mekhanizatsii zhivotnovodstva. 2017;(3(27)):91-97.

13. Savinykh P. A., Kazakov V. A., Moshonkin A. M. Eksperimental'no-teoreticheskie issledovaniya pitayushchego ustroystva plyushchilki zerna. [Experimental and theoretical studies of the feeding device of the grain crusher]. Vestnik Vserossiyskogo nauchno-issledovatel'skogo instituta mekhanizatsii zhivotnovodstva. 2019;(3(35)):61-68.

14. Odegov V. A., Komkin A. S., Shilin V. V. Issledovanie vliyaniya okruzhnoy skorosti val'tsov $i$ vlazhnosti materiala na osnovnye pokazateli rabochego protsessa dvukhstupenchatogo val'tsovogo stanka. [The influence of circumferential velocity of rollers and material moisture content on the main indicators of workflow of a two-step roller machine]. Permskiy Agrarnyy Vestnik = Perm Agrarian Journal. 2018; (1(21)):28-33. URL: https://www.elibrary.ru/item.asp?id=32664910

15. Pun'ko A. I., Romanchuk D. I., Savinykh V. N., Gud A. N. Analiz konstruktsiy val'tsovykh izmel'chiteley zernofurazha. [The analysis of designs of grain fodder roller]. Mekhanizatsiya i elektrifikatsiya sel'skogo khozyaystva. Mezhvedomstvennyy tematicheskiy sbornik. 2011;(45): 172-178. URL: https://www.elibrary.ru/item.asp?id=30716940

16. Savinykh V. N., Romanchuk D. I., Vorob'ev N. A. Rezul'taty ispytaniy plyushchilki vlazhnogo zerna PVZ-10. [The results of tests damp grain roller mill PVZ-10]. Mekhanizatsiya i elektrifikatsiya sel'skogo khozyaystva. Mezhvedomstvennyy tematicheskiy sbornik (k 80-letiyu so dnya obrazovaniya NAN Belarusi). 2008;(42): $210-214$. URL: https://www.elibrary.ru/item.asp?id=35369746

17. Vorob'ev N. A. Teoreticheskie issledovaniya proizvoditel'nosti val'tsovoy plyushchilki. [Theoretical studies of productivity of the roller crusher]. Agropanorama. 2008;(2):45-48. URL: https://rep.bsatu.by/handle/doc/1263

18. Dayneko V. A., Prishchepova E. M. Matematicheskoe modelirovanie moshchnosti val'tsovoy plyushchilki zerna. [Mathematical modeling of power of roller crusher of grain]. Ukrainian Food Journal. 2012; (3):40-49. URL: http://www.ufj.ho.ua/

Аграрная наука Евро-Северо-Востока /

Agricultural Science Euro-North-East, 2020;21(2):183-198 
19. Dayneko V. A., Prishchepova E. M. Teoreticheskoe obosnovanie proizvoditel'nosti val'tsovoy plyushchilkiizmel'chitelya. [Theoretical justification of the productivity of the roller crusher-grinder]. Agropanorama. 2012;(2):14-28. URL: https://rep.bsatu.by/handle/doc/7245

20. Shilo I. N., Vorob'ev N. A., Prishchepova E. M. K obosnovaniyu moshchnosti privoda val'tsov plyushchilki. [To substantiate the drive power of the crusher rollers]. Agropanorama. 2008;(3):25-28. URL: https://rep.bsatu.by/handle/doc/1280

21. Dayneko V. A., Prishchepova E. M. $K$ voprosu povysheniya proizvoditel'nosti $i$ snizheniya udel'nykh energozatrat val'tsovoy plyushchilki zerna. [On the issue of increasing productivity and reducing specific energy consumption of the grain roller crusher]. Agropanorama. 2013;(2):24-27.

URL: https://rep.bsatu.by/handle/doc/6398?mode=full

22. Prishchepov M. A., Gurin V. V., Prishchepova E. M., Ivanov D. M. Control device for interconnected frequency-controlled asynchronous electric drives with electric energy recovery (options): patent on the image: patent Republic of Belarus, no. 21618, 2018.

URL: https://ncip.by/upload/iblock/f5a/f5a1dfcb7efc24c148aeebb6b129fa29.pdf

23. Prishchepov M. A., Gurin V. V., Prishchepova E. M., Ivanov D. M. Method for controlling interconnected electric drives with electric energy recovery: patent on the image: patent Republic of Belarus, no. 19919, 2016. Afitsyyny byul. Nats. tsentr intelektual. ulasnastsi. 2016.

URL: https://ncip.by/upload/iblock/7b1/7b122278043fa35fd69d4258c4cb09ee.pdf

24. Dayneko V. A., Gurgenidze I. I., Prishchepova E. M. Obosnovanie tselevoy funktsii i kriteriya optimizatsii konstruktivnykh i tekhnologicheskikh parametrov sistemy elektroprivoda val'tsovykh plyushchilokizmel'chiteley zerna. [Substantiation of the target function and criterion for optimizing the design and technological parameters of the electric drive system of roller grain crusher-grinders]. Agropanorama. 2015;(4):30-35. URL: https://rep.bsatu.by/handle/doc/4176

25. Prishchepova E. M., Dayneko V. A. Method for controlling interconnected drives of roller grain crusher-grinders with electric energy recovery: patent Republic of Belarus, no. 21847, 2018.

URL: https://ncip.by/upload/iblock/b43/b4369672f12b7716e201e2bcd49634a5.pdf

\section{Сведения об авторах}

$\triangle$ Прищепов Михаил Александрович, доктор техн. наук, доцент, профессор кафедры электрооборудования сельскохозяйственных предприятий УО «Белорусский Государственный Аграрный Технический Университет», проспект Независимости, 99, г. Минск, Республика Беларусь, 220023,

ORCID: http://orcid.org/0000-0002-5359-3861, e-mail: pma.eshp@gmail.com

Дайнеко Владимир Александрович, к.т.н., доцент, заведующий кафедрой электрооборудования сельскохозяйственных предприятий УО «Белорусский Государственный Аграрный Технический Университет», проспект Независимости, 99, г. Минск, Республика Беларусь, 220023,

ORCID: http://orcid.org/0000-0002-9612-079X, e-mail: daineka49@gmail.com

Прищепова Елена Михайловна, старший преподаватель кафедры электрооборудования сельскохозяйственных предприятий УО «Белорусский Государственный Аграрный Технический Университет», проспект Независимости, 99, г. Минск, Республика Беларусь, 220023, ORCID: http://orcid.org/0000-0002-5598-4807, e-mail:pr.lena@tut.by

\section{Information about the authors}

$\triangle$ Mikhail A. Pryshchepau, DSc in Engineering, associate professor, professor at the Department of Electrical Equipment of Agricultural Enterprises, the Belarusian State Agrarian Technical University, 99 Nezavisimosti Avenue, Minsk, Republic of Belarus, 220023, ORCID: http://orcid.org/0000-0002-5359-3861, e-mail: pma.eshp@gmail.com

Vladimir A. Daineka, PhD in Engineering, associate professor, head of the Department of Electrical Equipment of Agricultural Enterprises, the Belarusian State Agrarian Technical University, 99 Nezavisimosti Avenue, Minsk, Republic of Belarus, 220023, ORCID: http://orcid.org/0000-0002-9612-079X, e-mail: daineka49@gmail.com

Alena M. Pryshchepava, senior lecturer, the Department of Electrical Equipment of Agricultural Enterprises, the Belarusian State Agrarian Technical University, 99 Nezavisimosti Avenue, Minsk, Republic of Belarus, 220023, ORCID: http://orcid.org/0000-0002-5598-4807, e-mail: pr.lena@tut.by

$\triangle$ - Для контактов / Corresponding author 